\title{
Use of an Outdoor Swimming Pool as Seasonal Heat Source in Heat Pump Applications
}

\author{
Giuseppe Emmi ${ }^{*}$, Alessia Natali ${ }^{1}$, Silvia Cesari ${ }^{1}$, Patrizio Fausti ${ }^{2}$, Michele Bottarelli $^{1}$ \\ ${ }^{1}$ Department of Architecture, University of Ferrara, Via Quartieri 8, Ferrara, Italy \\ ${ }^{2}$ Department of Engineering, University of Ferrara, Via Saragat 1, Ferrara, Italy
}

Corresponding Author Email: giuseppe.emmi@unife.it

https://doi.org/10.18280/ti-ijes.652-430

Received: 23 March 2021

Accepted: 17 May 2021

\author{
Keywords: \\ swimming pool, renewable sources, heat \\ pump, TRNSYS, energy saving
}

\begin{abstract}
The improvement of energy efficiency in the building sector is one of the most promising actions for achieving the energy and environmental goals of the European Community. The deep retrofit of buildings is obviously the best solution in terms of energy performance result. When the deep retrofit is not allowed or possible, the simple maintenance of the building envelope and plant is usually done to assure the operation over time. This type of intervention could require the installation of new HVAC systems that could include a HP, which nowadays represents one of the key devices for the energy saving and the sustainable development. This work regards the study of the energy performance of a swimming Pool Centre in North-East Italy. The objective of this work is the exploitation of an outdoor swimming pool as a heat source for a HP system. The HP system uses two different heat sources, the air and the water. The final SCOP of the double source HP system has been calculated and compared with an air source HP solution. This analysis has been carried out by means of dynamic energy simulations in TRNSYS environment.
\end{abstract}

\section{INTRODUCTION}

The building sector is one of the main contributors to the environmental issues that we are facing nowadays, due to its high energy consumption and related greenhouse gas emissions (GHGs). Therefore, the improvement of building energy efficiency is one of the most promising actions for achieving the energy and environmental goals of the European Community (EC). As widely known and discussed in literature, the building sector is responsible for $40 \%$ of the global energy consumption and for $36 \%$ of GHGs. Existing buildings represent the most part of the building stock and their renovation could significantly contribute to reach energy saving targets. About the $75 \%$ of the European Union (EU) building stock is energy inefficient and needs to be refurbished. This is one of the main reasons why a large part of the energy source is wasted instead of used for the real purpose [1]. All sectors consuming energy have to be included in this community path. The new environmental targets set by the EC within the 2030 climate and energy framework require at least $40 \%$ cuts in GHGs, the 32\% share for renewable energy and $32.5 \%$ improvement in energy efficiency [2].

Thinking about the low energy efficiency of the majority of the building stock, heat losses can be reduced by improving the thermal insulation of the building envelope and striving for smart solutions and energy efficient materials when building up new constructions. Nevertheless, these typologies of actions are not always possible for several reasons, which can also include economic aspects or restrictions from a regulatory and legislative point of view. When this happens, the maintenance is usually the only possible intervention on the buildings in order to assure their operation [3]. This type of intervention could require the installation of new Heating, Ventilation and Air Conditioning (HVAC) systems that may include a HP. Indeed, in the last decade one of the main discussed and investigated energy saving application is related the use of HP systems in substitution of the more diffused boiler systems $[4,5]$.

The energy-saving potential of heat pump technology is widely recognized in the building sector [6-8]. Heat pump systems can be distinguished on the basis of their heat source/sink, which could be air, ground and water. Compared to air source heat pumps (ASHP), ground and water source systems present a steady performance throughout all seasons. Indeed, water and ground sources are exposed to lower temperature fluctuations compared to the air. Thus, water source heat pump (WSHP) and ground source heat pump (GSHP) systems are characterized by a higher stability and limited temperature decay and, consequently, higher seasonal performance indicators $[9,10]$. More in detail, WSHP systems have more advantages in terms of energy-efficiency, ease of installation, and cost comparing to a ground source cooling and heating system. Considering the high specific heat capacity of water, particularly, water bodies were demonstrated to be a competent heat source and sink for heating and cooling $[11,12]$. WSHP systems can be classified by the type of water source, such as wastewater, raw water, underground water, and surface water [13]. Surface water source heat pump (SWSHP) can use river water [14], seawater [15], lake water, pond water [16], lagoon water, etc., and their installation cost is generally the lowest compared to other WSHP systems [17]. A growing number of studies have been focused on the assessment of the potential of WSHP integrated with different types of surface water bodies. Baik et al. [18] analyzed the application of seawater as a heat source for a heat pump. The system was found to be able to cover a large heating load and a significant improvement in terms of the coefficient of performance (COP), compared to conventional 
air-source systems, was demonstrated to be achievable with a series configuration. Chen et al. [19] investigated a lake water heat pump used to provide district cooling and heating. A higher COP was reported compared to the air source system operating at the same heat sink and source temperatures. Schibuola and Scarpa [9] carried out an experimental analysis of the performance of a SWHP using lagoon water in Venice, Italy. The system was demonstrated to allow a reduction of about $20 \%$ of the electricity consumption compared to an ASHP.

As the interest in SWSHP increases, the potential of using different water bodies as sources has been increasingly investigated. The use of swimming pools as a heat sink was proposed by several studies [20-22], which proved the feasibility of coupling the conditioning equipment for space cooling to outdoor swimming pools. Nevertheless, the use of swimming pools as a heat source for HPs has been rarely analyzed in literature [23].

On the contrary, taking into consideration swimming pools as facilities with energy demand to be met, a large body of literature studied the development of various heating technologies aiming to reduce energy use. Indeed, compared with other sports facilities, swimming pools have higher energy demand due to their high sensible, latent, and ventilation loads, and for the operation of circulation pumps [24]. However, the major energy use of swimming pool facilities is for heating. Heat is required not only to maintain a comfortable water temperature, but also to ensure indoor thermal comfort for the swimmers and visitors. A lot of energy is required to control the space air and pool water temperature, the relative humidity and air velocity over water surface [25]. The literature review conducted by Li et al. [26] considered both passive and active heating technologies for indoor swimming pools. Among the latter, solar collector, waste heat recovery, cogeneration technologies and heat pump systems, ranging from solar assisted heat pumps [27] to GSHP [28], were discussed. Similarly, the state-of-the-art review carried out by Katsaprakakis [29] compared alternative passive and active heating systems based on renewable energy sources in Southern Europe. Among active systems, most of the reviewed studies were focused on solar collector, heat recovery, and GSHP systems. Therefore, analysis of the literature uncovers that there is a lack of studies investigating the use of WSHP systems to meet heating energy demand of indoor swimming pools. As already mentioned before, SWHP systems using an outdoor swimming pool as heat source was analyzed in [23], but it was destined to provide space heating for a residential building, not for an indoor swimming pool.

Against this background, the present work analyzed the exploitation of an outdoor swimming pool, which is used only in the summer period, as a heat source for a double source HP system in winter. The HP was used to provide pool water heating and domestic hot water production to an indoor swimming Pool Centre in the North-East of Italy. The analysis was carried out by means of dynamic energy simulations conducted in TRNSYS environment.

\section{THE CASE STUDY}

The present work examines the case study of an Italian swimming Pool Centre located in the city of Ferrara in NorthEast Italy. A first energy analysis of the same building complex has been carried out and published in a previous paper [30]. In that work the analysis wanted to investigate a few possible actions to better manage the generation system of the pool and at the same time it evaluates how the reduction in evaporative mass could positively affect the reduction in energy consumption. Small changes at plant level were considered and limited to the building and to the indoor swimming pool of the Centre. The same plant layout and management has been assumed in the present work with small variations as described in the following of the text. In particular, the authors evaluated the advantages of adopting a new pool management approach and the effects of a new layout of the plant solutions both from the energy and economic point of view. In this last case the change of the layout did not modify deeply the system, but only a heat exchanger and a few valves were added in the original hydronic plant. In detail, the results clearly showed that the use of the thermal swimming pool cover significantly reduces the heat losses. At the same time, the exploitation of the already installed HP coupled with the new heat exchanger allows to improve the energy efficiency of the system, thus reducing the primary energy demand. The present study wants to investigate the possibility of using what is already existing in the Pool Centre and that is not employed during the winter period. In fact, the outdoor swimming pool is only used during the summer and it is not emptied. Therefore, it could be exploited as a thermal flywheel source for a dedicated water to water heat pump (WWHP).

\subsection{Description of the case study}

The thermal power plant of the Pool Centre is normally used both for HVAC of indoor spaces and for heating the water of the indoor swimming pool. The Centre consists of different thermal zones that can be summarized as follows: the pool zone, the changing area, the warehouse, the hall/bar zone and an unconditioned area. All the zones have a total conditioned area of about $5400 \mathrm{~m}^{2}$ and a relative net volume of about 19000 $\mathrm{m}^{3}$.

The thermal power plant consists of different devices used for heating: two condensing boilers with a size of $270 \mathrm{kWt}$ each, a cogeneration unit and an air to water heat pump (AWHP). A solar thermal collector field is also installed. Two storage tanks are used for the DHW production for a total of $4000 \mathrm{~L}$.

A sketch of the thermal power plant is shown in Figure 1. More detail about the case study can be found in [30] which describes the previous study on the same swimming Pool Centre.

As already described in the text, the Pool Centre has an outdoor swimming pool which is exclusively used during the summer, indicatively, from June to the beginning of September. During the winter period, the large amount of water is available for other uses until the Pool Centre starts with the cleaning and maintenance activities for the summer. The main idea of the present study is to evaluate the possibility of using this water volume to obtain an energy saving by the exploitation of this water as heat source for a WWHP.

The new WWHP will work in parallel together with the AWHP, or another possibility is the replacement of the two HPs with a hybrid HP which can use the two sources, air or water. The parallel operation of the HPs will be used in "or" operation mode, this means that only one of them will work while the other one will be off. 


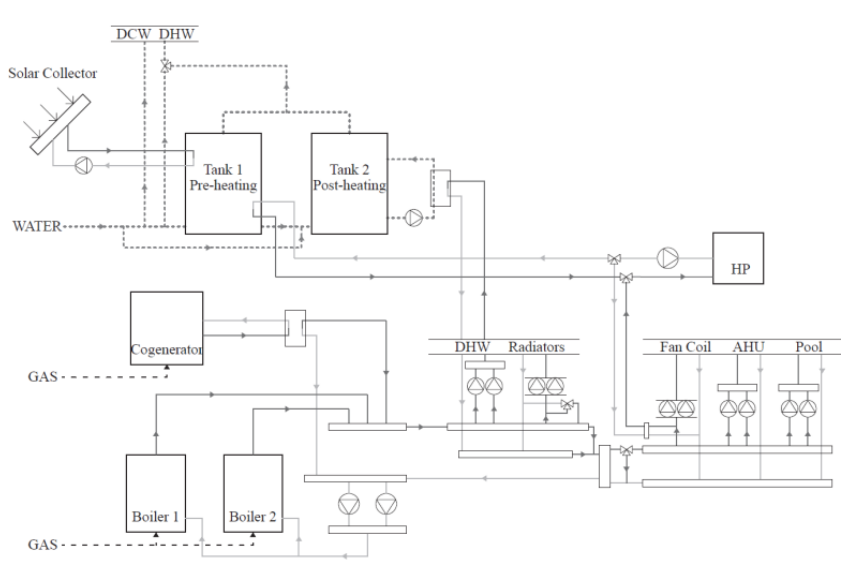

Figure 1. Sketch of the thermal power plant [30]

\section{METHODOLOGY}

Similarly to the study reported in [30], several dynamic simulations have been carried out using TRNSYS simulation tool. The energy model of the existing building and plant was calibrated in the previous study by means of monitoring data recorded during the winter period. Therefore, the model has been modified by adding the outdoor pool and the WWHP which were not originally included. Differently from the first energy model of the system, a detailed model of the AWHP and WWHP has been developed and used for this analysis. In particular, the energy performance of the HPs has been calculated considering the behavior of the compressors and the efficiency of the heat exchangers (condenser and evaporator). The size of the HPs is the same for the AWHP and WWHP respectively, and they use the same compressor. The approach used for the HP model is the same reported in [31]. The model of the HPs has been implemented in an Excel spreadsheet which is called from the Simulation Studio software (a part of TRNSYS package) at each timestep of the simulation by means of Type62. The choice of the HP to be used, between the air and the water source one, is done by considering the temperatures of the outdoor air and of the outdoor pool water. For this aim a simple code has been written in Simulation Studio for the management of the HP units.

\subsection{The Pool Centre energy model}

The Pool Centre is composed of three main parts: the building structure (which includes a hall, a snack bar and a changing zone), the indoor pool and the outdoor pool. The first two areas can be considered as active parts of the occupied space and are air-conditioned confined spaces during all the year regardless of the season. The outdoor pool, despite being a part of the Pool Centre, has to be assumed as a component of the thermal power plant. Indeed, it is regarded as a thermal storage or as a heat source in this context.

The dynamic model of the building was described with TRNBuild software, which is, as Simulation Studio, a part of TRNSYS package tool.

The shape of the outdoor pool is quite complex and, due to the limit of the simulation tool, an equivalent pool has been considered in the energy model. The Type of the software used in Simulation Studio requires several data to simulate the thermal behaviour of the pool. Outdoor pools are usually affected by several phenomena that contribute to decrease and increase the temperature of the water inside. The evaporation at the surface is influenced by the climate and, in normally use, during the summer period the pool needs the supply of fresh water for balancing the evaporation losses. Together with the previous latent exchange a sensible heat exchange occurs with the air and sky due to convective and radiative heat exchange respectively. In order to reduce these heat fluxes, and preserve the temperature of the water as much as possible, a thermal insulating overlay has been supposed above the surface of the pool. Thanks to this cover, also the evaporation phenomenon will be deeply reduced and for this reason it has been reasonable neglected in the present analysis. The outdoor pool has a volume of about $880 \mathrm{~m}^{3}$ and an area of $440 \mathrm{~m}^{2}$.

\subsection{The model of the heat pump}

The heat pump model works in heating mode since the energy analysis is focused on the winter period, using the outdoor pool as heat source for the WWHP. The model calculates the heat flux at the evaporator side and the electrical consumption of the compressor according to the equations which describe the behaviour of the compressor. This data is usually provided by the manufacturer of the compressor. The thermal capacity at the condenser side is calculated as the sum of the heat flux at the evaporator side and the $95 \%$ of the electrical consumption of the compressor. The $5 \%$ of the compressor load is considered by the model as thermal losses of the compressor envelope. The behaviour of the compressor is described by means of polynomial equations, which are function of the evaporating and condensing temperatures calculated in the model by an iterative process. The equations used in the HP model are reported in Eq. (1) and Eq. (2). The coefficients of the polynomials are different for the calculation of the heat flux at the evaporator and of the electrical consumption of the compressor. The values of these coefficients are reported at the end of the document in the appendix section.

$$
\begin{aligned}
\dot{W}_{e l}=a_{0}+a_{1} T_{e v} & +a_{2} T_{c d}+a_{3} T_{e v}^{2}+a_{4} T_{e v} T_{c d} \\
& +a_{5} T_{c d}^{2}+a_{6} T_{e v}^{3}+a_{7} T_{e v}^{2} T_{c d} \\
& +a_{8} T_{e v} T_{c d}^{2}+a_{9} T_{c d}^{3} \\
\dot{Q}_{e v}=b_{0}+b_{1} T_{e v} & +b_{2} T_{c d}+b_{3} T_{e v}^{2}+b_{4} T_{e v} T_{c d} \\
& +b_{5} T_{c d}^{2}+b_{6} T_{e v}^{3}+b_{7} T_{e v}^{2} T_{c d} \\
& +b_{8} T_{e v} T_{c d}^{2}+b_{9} T_{c d}^{3}
\end{aligned}
$$

The evaporation and condensation temperatures are calculated at each timestep by an iterative loop, considering a few constant boundary conditions. In this case, the main important boundary conditions are: the thermal efficiencies of both the condenser and the evaporator, the thermal approaches at the air to refrigerant heat exchanger, the mass flow rate and the inlet temperatures of the heat carrier fluids. The thermal efficiencies ( $\eta$ ) and the pinch point (PP), this last one chosen as thermal approach for the heat exchangers, are reported in Table 1.

Table 1. HP model - Properties of the heat exchangers

\begin{tabular}{ccccc}
\hline & \multicolumn{2}{c}{ AWHP } & \multicolumn{2}{c}{ WWHP } \\
& EV & CD & EV & CD \\
PP $\left[{ }^{\circ} \mathrm{C}\right]$ & 10 & - & - & - \\
$\eta[-]$ & - & 0.7 & 0.7 & 0.7 \\
\hline
\end{tabular}

The Table 2 and Table 3 show the energy performances of 
the heat pump units for the AWHP and WWHP respectively. This data has been calculated by means of the HP model.

Table 2. Properties of the AWHP

\begin{tabular}{|c|c|c|c|}
\hline $\mathrm{T}_{\mathrm{a}}$ & $\mathrm{T}_{\mathrm{u} \text { in }} / \mathrm{T}_{\mathrm{u} \text { out }}$ & $P_{\text {cond }}$ & $\mathrm{COP}$ \\
\hline-5 & \multirow{3}{*}{$24 / 29$} & 20.1 & 3.14 \\
\hline 5 & & 28.4 & 4.26 \\
\hline 15 & & 39.7 & 5.59 \\
\hline-5 & \multirow{3}{*}{$26 / 31$} & 20.3 & 3.28 \\
\hline 5 & & 28.7 & 4.42 \\
\hline 15 & & 40.0 & 5.76 \\
\hline-5 & \multirow{3}{*}{$29 / 33$} & 20.5 & 3.42 \\
\hline 5 & & 29.0 & 4.57 \\
\hline 15 & & 40.3 & 5.93 \\
\hline
\end{tabular}

Table 3. Properties of the WWHP

\begin{tabular}{|c|c|c|c|}
\hline $\mathrm{T}_{\mathrm{s} \text { in }} / \mathrm{T}_{\mathrm{s} \text { out }}$ & $\mathrm{T}_{\mathrm{u} \text { in }} / \mathrm{T}_{\mathrm{u} \text { out }}$ & $\mathrm{P}_{\text {cond }}$ & COP \\
\hline $14 / 11$ & \multirow{4}{*}{$24 / 29$} & 47.0 & 6.68 \\
\hline $10 / 7$ & & 41.2 & 6.06 \\
\hline $6 / 3$ & & 36.3 & 5.47 \\
\hline $4 / 1$ & & 33.8 & 5.17 \\
\hline $14 / 11$ & \multirow{4}{*}{$26 / 31$} & 46.5 & 6.48 \\
\hline $10 / 7$ & & 41.0 & 5.87 \\
\hline $6 / 3$ & & 35.8 & 5.28 \\
\hline $4 / 1$ & & 33.6 & 5.02 \\
\hline $14 / 11$ & \multirow{4}{*}{$29 / 33$} & 46.0 & 6.29 \\
\hline $10 / 7$ & & 40.6 & 5.69 \\
\hline $6 / 3$ & & 35.6 & 5.13 \\
\hline $4 / 1$ & & 33.4 & 4.86 \\
\hline
\end{tabular}

\subsection{The management of the HP units}

The HP units are controlled in order to make available the water pool source when the external air temperature is lower than the temperature switch $\left(\mathrm{T}_{\mathrm{sw}}\right)$ that is decided by the user. A set of switching temperatures has been considered in the simulations. A value for the minimum limit temperature of the pool is taken into account in the management rules in order to avoid the frosting of the water, since the heat carrier fluid in the pool is pure water without anti-freeze additive. The flowchart of the management of the heat pumps is reported in Figure 2. Three different cases have been considered in the energy analysis to evaluate the thermal load share due to different values of $\mathrm{T}_{\mathrm{sw}}$. The details of the control for each case are summarized in Table 4.

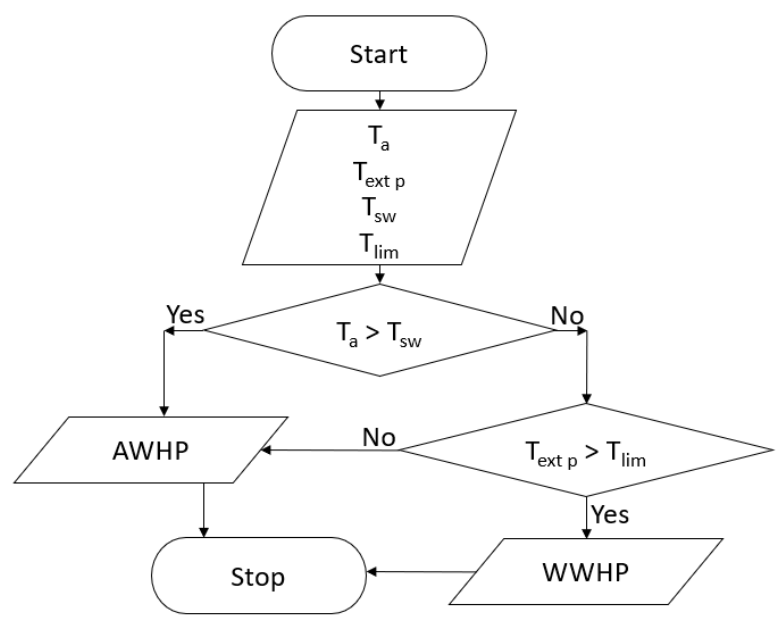

Figure 2. Control strategy of the HPs
Table 4. Properties of the control strategy of each case study

\begin{tabular}{ccc}
\hline Case Code & $\mathrm{T}_{\mathrm{sw}}\left[{ }^{\circ} \mathrm{C}\right]$ & $\mathrm{T}_{\lim }\left[{ }^{\circ} \mathrm{C}\right]$ \\
\cline { 1 - 2 } SW50 & 5 & \multirow{2}{*}{4} \\
\cline { 1 - 2 } SW25 & 2.5 & 4 \\
\cline { 1 - 2 } SW00 & 0 & \\
\hline
\end{tabular}

\section{THE SIMULATIONS}

The energy analysis reported in this paper is based on a preliminary dynamic model of the Pool Centre. This first research has been carried out with the aim of improving the energy performance of the entire building complex focusing on the historical management of the thermal power plant. A monitoring campaign of the operating conditions has been used for the calibration of the dynamic energy model and finally for the development of several hypothesis for a more efficient management of the thermal power plant [30]. The results of the study demonstrate that few energy saving actions can lead to a significant cut in terms of energy demand and consequently in GHG emissions. The two solutions proposed in the paper were the reduction of the evaporation rate of the swimming pool during the night and the exploitation of free energy by means of the AWHP already present in the thermal power plant but used only for the preheating of the DHW.

The dynamic model has been modified by replacing the existing HP with a couple of HPs that can use air or water as heat source.

The first simulation regards the analysis of the temperature trend of the outdoor water pool with the overlay on its surface. The outdoor pool is covered by a layer of thermal insulation used to reduce the heat losses of the water volume. Type 344 of TRNSYS simulation tool has been developed by their authors considering several assumptions that led to neglecting few heat fluxes between water volume and the surrounding boundary conditions. One of these assumptions is the heat exchange between the vertical and horizontal immersed walls of the pool to the surrounding ground. The main reason of this assumption is due to the fact that the walls of the pools are often bordering with underground technical rooms serving the pool itself. In particular, in our case study this assumption results in an underestimation of the heat flux from the ground to the water since the present analysis is focused on the behavior of the system in winter. As reference climate, the TRY (Test Reference Year) of Ferrara has been used in the simulations. As described, the outdoor pool surface is covered with insulation panels. Two different cases have been investigated for different values of panels thickness. The details of the panels are reported in Table 5. The trend of the pool temperature compared with the dry bulb temperature of the external air is reported in Figure 3 and Figure 4 for the case study of insulation panels thickness of $20 \mathrm{~mm}$ (Case A) and 50 $\mathrm{mm}$ (Case B) respectively. As it can be seen in the charts the temperature at the beginning of the heating period is obviously different in the two cases. From the trend of the pool temperature is evident the effect of the thermal insulating panels. The two analysis have been done for two years simulation period. The first year of simulation was aimed at bringing the system to the initial conditions, i.e., those conditions that characterize the system after one year of operation, at the end of the summer period. In particular, the outdoor pool was considered open to the users until the $15^{\text {th }}$ of September and therefore the water temperature was around 
$31^{\circ} \mathrm{C}$. Afterwards, the insulation panels were installed and the temperature decreased slowly, reaching the value of about $30^{\circ} \mathrm{C}$ on $15^{\text {th }}$ of October for the two case studies. The midOctober has been considered as the first day of the heating period according to Italian legislation while the end of the period is the $15^{\text {th }}$ of April.

The value of the starting temperature of the pool water at the beginning of the heating period can be used to previously evaluate which is the maximum free heat to exploit from the outdoor pool source. The maximum value of temperature difference useful for the heat pump over the heating season was considered as the difference between the starting temperature of the outdoor pool and the minimum temperature reachable, which means about $4^{\circ} \mathrm{C}$ to avoid frosting issue. The total amount of exploitable heat is about $26,5 \mathrm{MWh}$, with little difference between case $\mathrm{A}$ and $\mathrm{B}$. The difference will be more evident during the winter season due to the effect of the insulating panels.

Table 5. Properties of the insulating panels

\begin{tabular}{ccccc}
\hline Case Code & $\mathrm{S}_{\mathrm{pan}}[\mathrm{mm}]$ & $\lambda_{\mathrm{pan}}\left[\mathrm{W} /\left(\mathrm{m}^{*} \mathrm{~K}\right)\right]$ & $\alpha$ & $\varepsilon$ \\
\cline { 1 - 2 } $\mathrm{A}$ & 20 & 0.04 & 0.9 & 0.4 \\
\cline { 1 - 2 } $\mathrm{B}$ & 50 & 0.04 & & \\
\hline
\end{tabular}

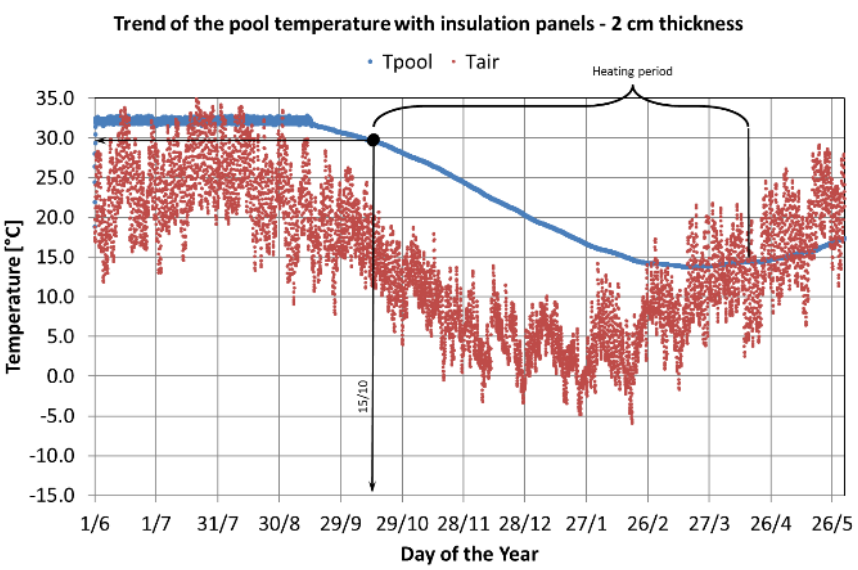

Figure 3. Case A - Trend of the pool temperature $-2 \mathrm{~cm}$

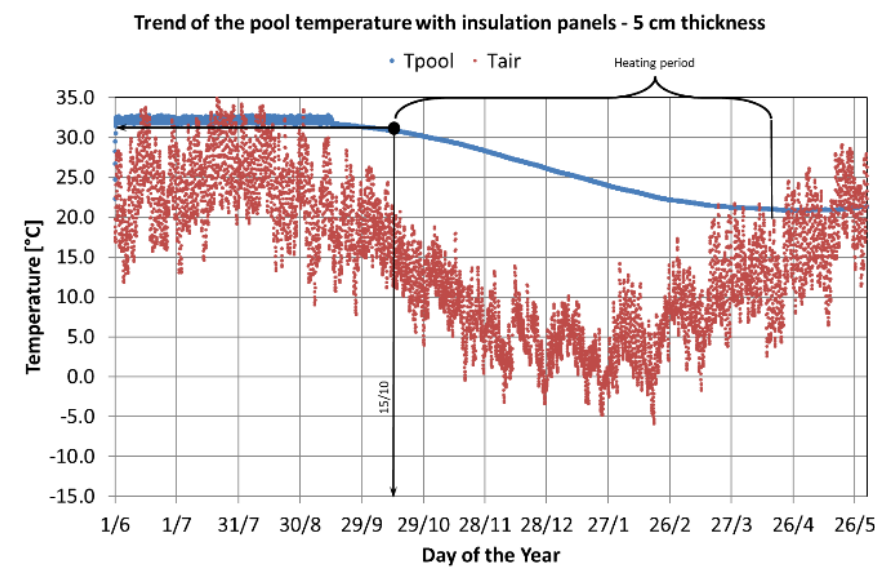

Figure 4. Case B - Trend of the pool temperature $-5 \mathrm{~cm}$

\section{RESULTS AND DISCUSSION}

A set of six simulations have been carried out by combining case A and B, for the two different values of thickness of the insulation panels, with the cases SW00, SW25 and SW50 related to the management of the HP. The main results of the simulations are summarized in Table 6.

The data in the table show the seasonal results in terms of thermal load share between the air source and the water source of the HP technology. The values represent the contribution of the HPs to the thermal power plant of the Pool Centre for the pre-heating of the DHW and the heating of the indoor pool water. The supply water temperature of the heat pumps to the DHW tank or to the indoor pool, to which the HPs were connected, is function of the inlet water temperature and of the thermal capacity available at the condenser side. This characteristic is function of several boundary conditions that change at each timestep. In detail, these are the air temperature, the inlet temperatures at the source and user sides, respectively. These temperature levels affect the energy performances of the compressor as described in the previous part of the paper and the compressor behavior is described by means of the Eq. 1 and Eq. (2).

Considering the management strategy used in the simulations, the results show a contribution of the WSHP between the $8 \%$ and $37 \%$ in terms of operating time for the case study ASW00 and BSW50. This result is strictly related to the climate of the location and to the $\mathrm{T}_{\mathrm{sw}}$. A comparative analysis of the heat loads highlights that the contribution of the WWHP ranges between the $12 \%$ and the $44 \%$ of the total HPs thermal load. The SCOP of the AWHP ranges between 4.58 and 4.92 while the WWHP energy performance reaches values between 6.20 and 7.41 .

In Figure 5, the trend of the water temperature of the outdoor pool is represented for the previous six case studies. Comparing the cases ASW50 and BSW50, the difference is the thickness of the insulation panels installed over the outdoor pool. From the values in the chart it can be seen that panels with a thickness of $50 \mathrm{~mm}$ make available a source temperature for the WWHP of about $4^{\circ} \mathrm{C}$ higher than the case with panels having a lower thickness. Furthermore, the availability of the outdoor pool to be used as heat source increases of about two weeks before reaching the limit temperature of $4^{\circ} \mathrm{C}$. Similarly, the same happens for the other case studies. For the cases ASW25 and BSW25 the temperatures differ of about $5^{\circ} \mathrm{C}$, while for the cases ASW50 and BSW50 the value is about $5.5^{\circ} \mathrm{C}$. The charts clearly show that a $\mathrm{T}_{\mathrm{sw}}$ equal to $0^{\circ} \mathrm{C}$ does not allow to exploit all the free heat available in the outdoor pool. The temperature of the water never reaches the minimum temperature of $4^{\circ} \mathrm{C}$ during the heating season.

High temperature values of the heat carrier fluid positively affect the energy performance of the WWHP by increasing the evaporation temperature and consequently the COP. On average, comparing the same $\mathrm{T}_{\mathrm{sw}}$, the use of better thermal insulation of the pool results in a decrease of about $13 \%$ of electric consumption between the case ASW00 and BSW00, $11 \%$ between ASW25 and BSW25 and 5\% between ASW500 and BSW50. The results reported in the table include the electric consumption of the auxiliary devices, fans and pump of the HPs, $130 \mathrm{~W}$ and $230 \mathrm{~W}$ for the AWHP and WWHP respectively.

The previous results describe the energy performance of the heat pump systems which can indistinctively use two available heat sources, external air and pool water, according to a specific management rule.

In order to make a comparison of the possible layouts of the HP system, a simulation has been carried out considering only 
the AWHP. This layout is similarly to what has been analyzed in the previous work on the same swimming Pool Centre [30]. The difference in terms of contribution to the thermal power plant and energy performance of the systems are summarized in Table 7.

The AWHP layout has been considered as baseline for this analysis and the main differences have been calculated. The total SCOP value of the two HPs, that are considered as one system, ranges between 4.64 and 5.37 from the case ASW00 to the case BSW50, while the AWHP has a SCOP of 4.38 .
As it can be seen in the table, the electrical demand of the HPs is almost the same for all the cases, but the available heat at the condenser side is different. This is due to the better working conditions of the HP, which are function of the temperature levels of the heat source at the evaporator side that increase the thermal capacity available at the condenser side. The use of the two HPs increases the useful heat between 7\% and $25 \%$ from the case ASW00 to the case BSW50.

Table 6. Results of the simulations

\begin{tabular}{ccccccccc}
\hline \multirow{3}{*}{ Case Stud } & $\begin{array}{c}\text { Q } \mathrm{Q}_{\text {cond }} \\
{\left[\mathrm{kWh}_{\mathrm{t}}\right]}\end{array}$ & $\begin{array}{c}\mathrm{Q}_{\mathrm{el}} \\
{\left[\mathrm{kWh}_{\mathrm{el}}\right]}\end{array}$ & $\begin{array}{c}\text { SCOP } \\
{[-]}\end{array}$ & $\begin{array}{c}\mathrm{OT} \\
{[\mathrm{h}]}\end{array}$ & $\begin{array}{c}\mathrm{Q}_{\text {cond }} \\
{\left[\mathrm{kWh}_{\mathrm{t}}\right]}\end{array}$ & $\begin{array}{c}\mathrm{Q}_{\mathrm{el}} \\
{\left[\mathrm{kWh}_{\mathrm{el}}\right]}\end{array}$ & $\begin{array}{c}\text { SCOP } \\
{[-]}\end{array}$ & $\begin{array}{c}\mathrm{OT} \\
{[\mathrm{h}]}\end{array}$ \\
\hline ASW00 & 47007 & 10489 & 4.48 & 1470 & 6345 & 1004 & 6.32 & 133 \\
ASW25 & 40482 & 8662 & 4.67 & 1212 & 16776 & 2808 & 5.97 & 380 \\
ASW50 & 37401 & 7963 & 4.70 & 1112 & 21388 & 3561 & 6.01 & 488 \\
BSW00 & 46803 & 10438 & 4.48 & 1462 & 7507 & 1044 & 7.19 & 134 \\
BSW25 & 40665 & 8701 & 4.67 & 1218 & 19053 & 2881 & 6.61 & 380 \\
BSW50 & 34922 & 7251 & 4.82 & 1011 & 27084 & 4304 & 6.29 & 582 \\
\hline
\end{tabular}

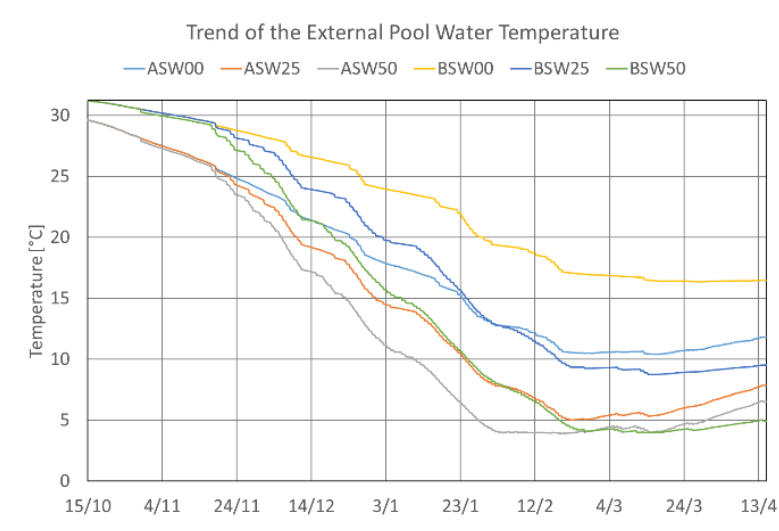

Figure 5. Temperature of the outdoor pool water

Table 7. Results of the comparison with the AWHP

\begin{tabular}{cccc}
\hline & $\mathrm{Q}_{\text {cond }} / \Delta \mathrm{Q}_{\text {cond }}$ & $\mathrm{Q}_{\mathrm{el}} / \Delta \mathrm{Q}_{\mathrm{el}}$ & $\mathrm{SCOP}_{\text {tot }}$ \\
\hline & {$\left[\mathrm{kWh}_{\mathrm{t}} / \%\right]$} & {$\left[\mathrm{kWh}_{\mathrm{el}} / \%\right]$} & {$[-]$} \\
AWHP & $49688 /-$ & $11355 /-$ & 4.38 \\
$\mathrm{ASW00}$ & $53352 /+7 \%$ & $11492 /+1 \%$ & 4.64 \\
ASW25 & $57258 /+15 \%$ & $11470 /+1 \%$ & 4.99 \\
ASW50 & $58789 /+18 \%$ & $11524 /+1 \%$ & 5.10 \\
BSW00 & $54310 /+9 \%$ & $11482 /+1 \%$ & 4.73 \\
BSW25 & $59718 /+20 \%$ & $11582 /+2 \%$ & 5.16 \\
BSW50 & $62006 /+25 \%$ & $11555 /+2 \%$ & 5.37 \\
\hline
\end{tabular}

\section{CONCLUSION}

The present study analyses the possibility of using the water of an outdoor swimming pool of an existing Pool Centre located in North-East Italy as heat source for HP application. The results of the simulations showed that:

- the use of thermal insulation panels on the surface of the pool limits the decrease in water temperature, thus improving the energy performance of the WWHP. The increase in the heat supplied to the thermal power plant by the WWHP ranges between $18 \%$ and $25 \%$;

- the $\mathrm{T}_{\mathrm{sw}}$ is a key point for the maximum exploitation of the free heat available in the outdoor pool water;
- the use of a dual source HP improves the energy performance of the AWHP because of its operation with higher air temperature;

- the global COP of the double source system reaches a value of 5.37 , corresponding to an increase of $22 \%$ if compared to the air source HP application, which corresponds to an energy saving of about $19 \%$.

\section{REFERENCES}

[1] European Commission - Department: Energy. In focus: Energy efficiency in buildings. https://ec.europa.eu/info/news/focus-energy-efficiencybuildings-2020-feb-17_en, accessed on Mar. 2021.

[2] European Commission. 2030 climate \& energy framework.

https:/ec.europa.eu/clima/policies/strategies/2030_en, accessed on Mar. 2021.

[3] Scoccia, R., Toppi, T., Aprile, M., Motta, M. (2018). Absorption and compression heat pump systems for space heating and DHW in European buildings: Energy, environmental and economic analysis. Journal of Building Engineering, 16: 94-105. https://doi.org/10.1016/j.jobe.2017.12.006

[4] Lin, H., Clavreul, J., Jeandaux, C., Crawley, J., Butnar, I. (2021). Environmental life cycle assessment of heating systems in the UK: Comparative assessment of hybrid heat pumps vs. condensing gas boilers. Energy and Buildings, 240: 110865. https://doi.org/10.1016/j.enbuild.2021.110865

[5] Bianco, V., Scarpa, F., Tagliafico, L.A. (2017). Estimation of primary energy savings by using heat pumps for heating purposes in the residential sector. Applied Thermal Engineering, 114: 938-947. https://doi.org/10.1016/j.applthermaleng.2016.12.058

[6] Sarbu, I., Sebarchievici, C. (2014). General review of ground-source heat pump systems for heating and cooling of buildings. Energy and Buildings, 70: 441-454. https://doi.org/10.1016/j.enbuild.2013.11.068

[7] Guo, X., Goumba, A.P. (2018). Air source heat pump for 
domestic hot water supply: Performance comparison between individual and building scale installations. Energy, 164: 794-802. https://doi.org/10.1016/j.energy.2018.09.065

[8] Hedegaard, K., Balyk, O. (2013). Energy system investment model incorporating heat pumps with thermal storage in buildings and buffer tanks. Energy, 63: 356365. https://doi.org/10.1016/j.energy.2013.09.061

[9] Schibuola, L., Scarpa, M. (2016). Experimental analysis of the performances of a surface water source heat pump. Energy and Buildings, 113: 182-188. https://doi.org/10.1016/j.enbuild.2015.12.048

[10] Yang, H., Cui, P., Fang, Z. (2010). Vertical-borehole ground-coupled heat pumps: A review of models and systems. Applied Energy, 87(1): 16-27. https://doi.org/10.1016/j.apenergy.2009.04.038

[11] Ma, W., Kim, M.K., Hao, J. (2019). Numerical simulation modeling of a GSHP and WSHP system for an office building in the Hot Summer and Cold Winter Region of China: A Case Study in Suzhou. Sustainability, 11(12): 3282. https://doi.org/10.3390/su11123282

[12] Valancius, R., Singh, R.M., Jurelionis, A., Vaiciunas, J. (2019). A review of heat pump systems and applications in cold climates: Evidence from Lithuania. Energies, 12(22): 4331. https://doi.org/10.3390/en12224331

[13] Jung, Y., Kim, J., Kim, H., Nam, Y., Cho, H., Lee, H. (2021). Comprehensive multi-criteria evaluation of water source heat pump systems in terms of building type, water source, and water intake distance. Energy and Buildings, 236: 110765. https://doi.org/10.1016/j.enbuild.2021.110765

[14] Jung, Y., Kim, J., Kim, H., Yun, R., Park, C., Nam, Y. (2021). Comprehensive feasibility investigation of river source heat pump systems in terms of life cycle. Applied Thermal Engineering, 188: 116655. https://doi.org/10.1016/j.applthermaleng.2021.116655

[15] Jia, X., Duanmu, L., Shu, H. (2017). Effect of seawater intake methods on the performance of seawater source heat pump systems in cold climate areas. Energy and Buildings, 153: 317-324. https://doi.org/10.1016/j.enbuild.2017.08.016

[16] Ramamoorthy, M., Jin, H., Chaisson, A.D., Spitler, J.D. (2001). Optimal sizing of hybrid ground-source heat pump systems that use a cooling pond as a supplemental heat rejecter-A system simulation approach. Transactions-American Society of Heating Refrigerating and Air Conditioning Engineers, 107(1): 26-38.

[17] $\mathrm{Yu}, \mathrm{S}$. (2018). Introduction of water source heat pump system. Handbook of Energy Systems in Green Buildings, R. Wang and X. Zhai, eds.; Berlin, DE: Springer, 1-48. https://doi.org/10.1007/978-3-66249088-4_4-1

[18] Baik, Y.J., Kim, M., Chang, K.C., Lee, Y.S., Ra, H.S. (2014). Potential to enhance performance of seawatersource heat pump by series operation. Renewable Energy, 65:

236-244. https://doi.org/10.1016/j.renene.2013.09.021

[19] Chen, X., Zhang, G., Peng, J., Lin, X., Liu, T. (2006). The performance of an open-loop lake water heat pump system in south China. Applied Thermal Engineering, 26(17-18): 2255-2261. https://doi.org/10.1016/j.applthermaleng.2006.03.009

[20] Woolley, J., Harrington, C., Modera, M. (2011). Swimming pools as heat sinks for air conditioners:
Model design and experimental validation for natural thermal behavior of the pool. Building and Environment, 46(1): 187-195. https://doi.org/10.1016/j.buildenv.2010.07.014.

[21] Harrington, C., Modera, M. (2013). Swimming pools as heat sinks for air conditioners: California feasibility analysis. Energy and Buildings, 59: 252-264. https://doi.org/10.1016/j.enbuild.2012.12.038

[22] Hunt, J.D., Zakeri, B., Leal Filho, W., Schneider, P.S., Weber, N.A.B., Vieira, L.W., Ermel, C., Castro, N.J., Barbosa, P.S.F., Nascimento, A., Mastrucci, A. (2021). Swimming pool thermal energy storage, an alternative for distributed cooling energy storage. Energy Conversion and Management, 230: 113796. https://doi.org/10.1016/j.enconman.2020.113796

[23] Cardemil, J.M., Schneider, W., Behzad, M., Starke, A.R. (2021). Thermal analysis of a water source heat pump for space heating using an outdoor pool as a heat source. Journal of Building Engineering, 33: 101581. https://doi.org/10.1016/j.jobe.2020.101581

[24] Kampel, W., Aas, B., Bruland, A. (2013). Energy-use in Norwegian swimming halls. Energy and Buildings, 59: 181-186. https://doi.org/10.1016/j.enbuild.2012.11.011

[25] Sun, P., Wu, J.Y., Wang, R. Z., Xu, Y.X. (2011). Analysis of indoor environmental conditions and heat pump energy supply systems in indoor swimming pools. Energy and Buildings, 43(5): 1071-1080. https://doi.org/10.1016/j.enbuild.2010.08.004

[26] Li, Y., Nord, N., Huang, G., Li, X. (2021). Swimming pool heating technology: A state-of-the-art review. Build. Simul, 14: 421-440. https://doi.org/10.1007/s12273-0200669-3

[27] Li, Y., Nord, N., Huang, G., Li, X. (2020). Swimming pool heating technology: A state-of-the-art review. In Building Simulation, 100: 309-317. https://doi.org/10.1016/j.apenergy.2012.05.058

[28] Chow, T.T., Bai, Y., Fong, K.F., Lin, Z. (2012). Analysis of a solar assisted heat pump system for indoor swimming pool water and space heating. Applied Energy, 100: 309-317. https://doi.org/10.1016/j.apenergy.2012.05.058

[29] Katsaprakakis, D.A. (2015). Comparison of swimming pools alternative passive and active heating systems based on renewable energy sources in Southern Europe. Energy, 81: 738-753. https://doi.org/10.1016/j.energy.2015.01.019

[30] Natali, A., Bottarelli, M., Fausti, P. (2020). A methodology of energy optimization in indoor swimming pool. TI-IJES, 64(2-4): 135-142. https://doi.org/10.18280/ti-ijes.642-402

[31] Vivian, J., Emmi, G., Zarrella, A., Jobard, X., Pietruschka, D., De Carli, M. (2018). Evaluating the cost of heat for end users in ultra low temperature district heating networks with booster heat pumps. Energy, 153: 788-800. https://doi.org/10.1016/j.energy.2018.04.081

\section{NOMENCLATURE}

$\begin{array}{ll}\text { ASHP } & \text { Air Source Heat Pump } \\ \text { AWHP } & \text { Air to Water Heat Pump } \\ \text { CD } & \text { Condenser } \\ \text { COP } & \text { Coefficient Of Performance } \\ \text { DHW } & \text { Domestic Hot Water }\end{array}$




$\begin{array}{ll}\text { EC } & \text { European Community } \\ \text { EU } & \text { European Union } \\ \text { EV } & \text { Evaporator } \\ \text { GHG } & \text { GreenHouse Gas } \\ \text { GSHP } & \text { Ground Source Heat Pump } \\ \text { HP } & \text { Heat Pump } \\ \text { HVAC } & \text { Heating Ventilation Air Conditioning } \\ \text { P } & \text { Power, Heat Flux, Load } \\ \text { PP } & \text { Pinch Point } \\ \text { Q } & \text { Energy, Heat, Heat Flux } \\ \text { OT } & \text { Operating Time } \\ \text { SCOP } & \text { Seasonal COP } \\ \text { SWSHP } & \text { Surface Water Source Heat Pump } \\ \text { T } & \text { Temperature } \\ \text { TRY } & \text { Test Reference Year } \\ \text { W } & \text { Electric absorption, W } \\ \text { WSHP } & \text { Water Source Heat Pump } \\ \text { WWHP } & \text { Water to Water Heat Pump }\end{array}$

\section{Greek symbols}

$\begin{array}{ll}\alpha & \text { Absorption Coefficient } \\ \Delta & \text { Difference } \\ \varepsilon & \text { Emissivity } \\ \eta & \text { Efficiency } \\ \lambda & \text { Thermal Conductivity, } \mathrm{W} \mathrm{m}^{-1} \mathrm{~K}^{-1}\end{array}$

\section{Subscripts}

$\begin{array}{ll}\begin{array}{l}\text { Cond, cd } \\ \text { el }\end{array} & \text { Condenser } \\ \text { Evap, ev } & \text { Electric } \\ \text { ext } & \text { Evaporator } \\ \text { in } & \text { External } \\ \text { lim } & \text { Inlet } \\ \text { out } & \text { Limit } \\ \text { p } & \text { outlet } \\ \text { pan } & \text { pool } \\ \text { s } & \text { panel } \\ \text { sw } & \text { Source } \\ \text { tot } & \text { Switch } \\ \mathrm{u} & \text { Total } \\ & \text { User }\end{array}$

\section{APPENDIX}

Coefficients of the polynomial's compressor

\begin{tabular}{cccc}
\hline & $W_{e l}$ & $\dot{Q}_{e v}$ \\
\hline$a_{0} / b_{0}$ & 5390.86936 & $/$ & 30381.02123 \\
$a_{1} / b_{1}$ & 34.2768865 & $/$ & 1113.45717 \\
$a_{2} / b_{2}$ & 26.8654242 & $/$ & 82.3548428 \\
$a_{3} / b_{3}$ & -0.80887 & $/$ & 20.0342 \\
$a_{4} / b_{4}$ & 1.498507 & $/$ & 2.174449 \\
$a_{5} / b_{5}$ & -0.43322 & $/$ & -5.67342 \\
$a_{6} / b_{6}$ & -0.01363 & $/$ & 0.133071 \\
$a_{7} / b_{7}$ & 0.037614 & $/$ & -0.12259 \\
$a_{8} / b_{8}$ & -0.03559 & $/$ & -0.09169 \\
$a_{9} / b_{9}$ & 0.024027 & $/$ & 0.020918 \\
\hline
\end{tabular}

